\title{
Correction to: Tumor-associated neutrophils induce EMT by IL-17a to promote migration and invasion in gastric cancer cells
}

Sen Li ${ }^{1,2}$, Xiliang Cong ${ }^{1}$, Hongyu Gao ${ }^{1}$, Xiuwen Lan ${ }^{1}$, Zhiguo Li ${ }^{1}$, Wenpeng Wang ${ }^{3}$, Shubin Song ${ }^{1}$, Yimin Wang ${ }^{1}$, Chunfeng Li $i^{1}$, Hongfeng Zhang ${ }^{1}$, Yuzhou Zhao ${ }^{2^{*}}$ and Yingwei Xue ${ }^{1 *}$

\section{Correction to: J Exp Clin Cancer Res (2019) 38: 6 https://doi.org/10.1186/s13046-018-1003-0}

In the publication of this article [1], there is an error in the order of the authors and the affiliations. The revised order of the authors and affiliations has now been included in this correction.

The corrected correspondence author order and author affiliation information is as given hereafter:

Sen $\mathrm{Li}^{1,2}$, Xiliang Cong ${ }^{1}$, Hongyu Gao ${ }^{1}$, Xiuwen $\mathrm{Lan}^{1}$, Zhiguo $\mathrm{Li}^{1}$, Wenpeng Wang ${ }^{3}$, Shubin Song ${ }^{1}$, Yimin Wang ${ }^{1}$, Chunfeng $\mathrm{Li}^{1}$, Hongfeng Zhang ${ }^{1}$, Yuzhou Zhao ${ }^{2^{*}}$ and Yingwei Xue ${ }^{1^{*}}$

1 Department of Gastroenterological Surgery, Harbin Medical University Cancer Hospital, 150 Ha Ping Road, Harbin 150081, China.

2 Department of General Surgery, The Affiliated Cancer Hospital of Zhengzhou University, 127 Dong Ming Road, Zhengzhou 450008, China.

3 Department of Gynecologic Oncology, Cancer Hospital Chinese Academy of Medical Sciences \& Peking Union Medical College, Beijing, China.

\section{Author details}

'Department of Gastroenterological Surgery, Harbin Medical University Cancer Hospital, $150 \mathrm{Ha}$ Ping Road, Harbin 150081, China. ${ }^{2}$ Department of General Surgery, The Affiliated Cancer Hospital of Zhengzhou University, 127 Dong Ming Road, Zhengzhou 450008, China. ${ }^{3}$ Department of Gynecologic Oncology, Cancer Hospital Chinese Academy of Medical Sciences \& Peking Union Medical College, Beijing, China.
Received: 23 March 2019 Accepted: 23 March 2019

Published online: 26 April 2019

\section{Reference}

1. Li S, Cong X, Gao H, et al. Tumor-associated neutrophils induce EMT by IL-17a to promote migration and invasion in gastric cancer cells. J Exp Clin Cancer Res. 2019;38(6) https://doi.org/10.1186/s13046-018-1003-0.

*Correspondence: 15776835073@163.com; xueyingwei@hrbmu.edu.cn

2Department of General Surgery, The Affiliated Cancer Hospital of

Zhengzhou University, 127 Dong Ming Road, Zhengzhou 450008, China

'Department of Gastroenterological Surgery, Harbin Medical University

Cancer Hospital, 150 Ha Ping Road, Harbin 150081, China

Full list of author information is available at the end of the article

(c) The Author(s). 2019 Open Access This article is distributed under the terms of the Creative Commons Attribution 4.0 International License (http://creativecommons.org/licenses/by/4.0/), which permits unrestricted use, distribution, and reproduction in any medium, provided you give appropriate credit to the original author(s) and the source, provide a link to the Creative Commons license, and indicate if changes were made. The Creative Commons Public Domain Dedication waiver (http://creativecommons.org/publicdomain/zero/1.0/) applies to the data made available in this article, unless otherwise stated. 